\title{
Advanced carcinoma of the oropharynx: survival analysis comparing two treatment modalities
}

\section{Patrícia Carlos CALDEIRA(a)}

Mara Juliana Fagundes BONARDI(a)

Esther Rodrigues Mansur PANTUZZO(b)

João Marcos Arantes SOARES(b)

Andréa Maria Lopez SOTO(a)

Maria Cássia Ferreira AGUIAR ${ }^{(a)}$

Alexandre Andrade SOUSA(b) (D)

(a) Universidade Federal de Minas Gerais UFMG, School of Dentistry, Department of Oral Pathology and Surgery, Belo Horizonte, MG, Brazil.

(b) Universidade Federal de Minas Gerais UFMG, Hospital das Clínicas, Department of Surgery of the School of Medicine and Head and Neck Surgery, Belo Horizonte, MG, Brazil.

Declaration of Interests: The authors certify that they have no commercial or associative interest that represents a conflict of interest in connection with the manuscript.

\section{Corresponding Author:}

Patrícia Carlos Caldeira

E-mail: pccaldeira@ufmg.br;

pat_caldeira@yahoo.com.br

https://doi.org/10.1590/1807-3107bor-2020.vol34.0032

Submitted: August 22, 2019

Accepted for publication: November 27, 2019

Last revision: March 4, 2020
Abstract: About 92,000 new cases of oropharynx carcinoma are expected to occur annually worldwide. There is no consensus about the best therapy for these advanced tumors. The objective of the present study was to evaluate overall and disease-free survival rates of patients with advanced oropharynx squamous cell carcinoma, comparing surgery + radiotherapy with chemotherapy + radiotherapy. Medical records of patients were reviewed. Previously treated tumors were excluded. Clinical, demographic and microscopic information was collected, and p16 staining was performed. Kaplan-Meier survival curves were plotted. Forty-seven cases were included, 41 men and 6 women, having a mean age of 56.3 years. Most patients were smokers (85.1\%) and consumed alcohol (74.5\%). Patients were stage III (21.3\%) or IV (78.7\%). Most lesions affected the base of the tongue (36.2\%). Of the 23 cases available for p16 testing, 3 were positive (13.0\%). There was no difference between the overall and the disease-free survival rates for the two treatment modalities ( $p>0.05$ ), even when only resectable tumors were compared. Seventeen cases experienced recurrence (36.2\%); 16 (34.0\%) patients remained alive without disease; 15 (31.9\%) died due to disease; 9 (19.2\%) were recurrent at the last follow-up. The two treatment protocols were equally efficient in treating advanced oropharynx squamous cell carcinoma, since both promoted similar overall and disease-free survival rates. The results and interpretations related herein mostly regard "conventional" oropharyngeal squamous cell carcinomas, as opposed to HPV-associated tumors.

Keywords: Oropharynx; Oropharyngeal Neoplasms; Carcinoma, Squamous Cell; Therapeutics; Survival.

\section{Introduction}

The oropharynx encompasses soft palate, tonsils, base of tongue, uvula, pharynx wall and vallecula. ${ }^{1,2}$. Oropharynx squamous cell carcinoma (OP-SCC) had an annual global incidence of 92,887 cases and 51,005 deaths worldwide $^{3}$ in 2018. Men are more affected than women, usually in the $5^{\text {th }}$ to $7^{\text {th }}$ decades of life. ${ }^{4}$ The most relevant etiological factors are smoking habit, alcohol consumption ${ }^{4}$ and human papilloma virus (HPV) ${ }^{5,6,7}$ Clinical staging of the tumors is based on the TNM classification system..$^{8,9}$ There is no consensus regarding the treatment of advanced cases of the disease. 
First line treatment should include surgery (Surg) and radiotherapy (RT), when clear margins can be achieved with surgery, ${ }^{10,11}$ or else platinum-based chemoradiation $(\mathrm{CT}+\mathrm{RT}){ }^{2,12}$

Disease control depends on the extension and site of the primary tumor, but neck involvement is the major prognostic factor. Recurrences are common (40-50\%) and commonly develop within two years after treatment. ${ }^{13,14}$ The prognosis is unfavorable, with survival rates as low as $58 \%$ in 2 years and $25 \%$ in 5 years. ${ }^{12,14,17}$ Bone invasion, surgical margins, perineural and perivascular invasion, extracapsular spread, and histological grade, are predictors of loco-regional recurrence and a low survival rate.

HPV has been associated with some head and neck cancers, especially those of the oropharynx. ${ }^{18,19,20}$ Importantly, there is an intriguing geographic disparity in the prevalence of HPV-positive head and neck cancers. The United States harbors a high prevalence $(60 \%)$, Western Europe has moderate proportions (31\%), and Brazil shows low indexes (4\%) of HPV16-positive OP-SCC. ${ }^{19}$ Since HPV-positive tumors have a better treatment response than HPVnegative ones, and a more favorable prognosis, ${ }^{21,22}$ the last American Joint Committee on Cancer (AJCC) Staging Manual now classifies OP-SCC according to its HPV status, as assessed by p16 immunohistochemistry., ${ }^{9,23}$

The main goal of this study was to compare the survival rates of patients submitted to two different treatment modalities for advanced oropharynx carcinoma, namely surgery plus radiotherapy (Surg+RT) and chemotherapy plus radiotherapy $(\mathrm{CT}+\mathrm{RT})$. Another goal was to evaluate the effect of resectability on the survival rates.

\section{Methodology}

The study protocol was approved by the Research Ethics Committee of the Federal University of Minas Gerais (CAAE 54987815.1.0000.5149). The patients gave their written consent for participation in the study.

A cross-sectional observational study was performed according to STROBE guidelines. Medical files from the Head and Neck Surgery Department of the Hospital das Clínicas of the Federal University of Minas Gerais (UFMG) (Brazil) were reviewed retrospectively from 2005 to 2015 . The inclusion criteria comprised diagnosis of OP-SCC, no previous treatment, clinical TNM stage III and IV (AJCC $7^{\text {th }}$ edition), and treatment performed at the Hospital das Clínicas UFMG. Patients with resectable tumors received Surg+RT, whereas those with unresectable tumors, or who refused the surgical approach were treated by $\mathrm{CT}+\mathrm{RT}$. The exclusion criteria were previously treated tumors, $\mathrm{T} 1$ and $\mathrm{T} 2$ tumors, under two-year follow-up period (as of the surgery or initial chemoradiotherapy date).

Information regarding the clinic and demographic features, and the response to treatment, were collected from the medical records. Variables included age, sex, smoking habit, alcohol intake, TNM staging, subsite, status at last follow-up, tumor resectability (criteria for unresectability: cervical N3 metastasis invading the common carotid artery or the skull base; primary tumor infiltrating the skull base and the internal carotid artery; involvement of the prevertebral fascia), and treatment modality.

The tumor samples (biopsy and/or surgical resection specimen) of the patients were retrieved from the files of the Laboratory of Pathologic Anatomy of the Hospital das Clínicas of UFMG and of the Hospital da Baleia. These samples were submitted to immunohistochemistry for p16 (CINtec ${ }^{\circledR}$ p16 Histology, ready-to-use, clone E6H4 ${ }^{\mathrm{TM}}$, Roche, USA, code 06695230001). A sample of OP-SCC known to be p16-positive was included as the positive control. Negative control was obtained by omission of the primary antibody. The immunostaining was evaluated by two independent observers (A.M.L.S. and P.C.C.), according to criteria proposed by Lydiatt et al. ${ }^{23}$ In brief, p16 overexpression was established when moderate to intense $(+2 / 3)$ staining was seen diffusely $(\geq 75 \%)$ in the tumor. Nuclear and cytoplasmic staining were considered when assessing the staining. Cytoplasmic coloration alone was considered unspecific. The cases were classified as positive or negative.

SPSS ${ }^{\circledR}$ version 19.0 and GraphPad Prism 7 software were used for the statistics. Descriptive analyses were performed. Pearson $c^{2}$ and Student's t-test were used to compare data regarding the clinical, 
demographic and microscopic characteristics of the two treatment groups. Kaplan-Meier survival analysis was conducted, and the curves were compared by the log-rank test. P-values $<0.05$ were considered significant.

\section{Results}

From 2005 to 2015, 75 patients were treated for advanced OP-SCC. Twenty-eight patients were excluded due to incomplete data on their medical records, rendering a final sample of 47 cases. Eighteen patients (38.3\%) had resectable tumors and received Surg+RT for treatment. Twenty-nine (61.7\%) individuals were treated with CT+RT (eighteen [62.1\%] with unresectable tumors, and eleven [37.9\%] patients who refused surgical treatment, despite having a resectable tumor).

Clinical and demographic data are presented in Table 1. All the variables shown in Table 1 were statistically similar between the two treatment groups ( $\mathrm{p}>0.05)$, except for $\mathrm{N}$ stage $(\mathrm{p}<0.05)$. Middle-aged men, with smoking and drinking habits, composed the majority of the sample. Tumors were located mainly at the base of the tongue and were staged as T4N0 and TNM IV. Seventeen tumors were moderately differentiated and three were well differentiated. The remaining afforded no information regarding histological differentiation. Of the 23 cases made available for p16 testing, three $(13.0 \%)$ tumors were positive. The other tumor samples could not be retrieved from the laboratory files, and were therefore not tested for p16. Two patients with $\mathrm{p} 16+$ tumors were non-smokers and non-drinkers, whereas the third case reported practicing these habits.

When comparing only the patients with resectable tumors, according to the treatment modality (Surg+RT vs. CT+RT), they presented similar clinical and demographic profiles ( $p>0.05)$, except for the tumor subsite $(p<0.05)$ and the recurrence site $(p=0.055)$ (Table 1). Tumors of the base of the tongue and the lateral wall were more common in the Surg+RT group, whereas soft palate lesions were more frequent in the $\mathrm{CT}+\mathrm{RT}$ group. Local or regional recurrence occurred only in the Surg+RT group.
Concerning the follow-up duration (mean 34.91 months) and response to treatment, 17 (36.2\%) cases experienced recurrence. Sixteen (34.0\%) patients remained alive without disease at the last follow-up, 15 (31.9\%) died due to disease, and 9 (19.2\%) were recurrent at the last follow-up (local, regional, or loco-regional) (Table 1).

Table 2 depicts the surgical treatment performed for the 18 patients treated with Surg+RT.

Survival analysis revealed similar overall and disease-free survival rates for patients treated with Surg+RT and CT+RT ( $p>0.05$, Figure A, B). Noteworthily, deaths in both groups occurred mostly at the beginning of the follow-up period, precisely during the first 24 months (Figure A). At this timepoint, $60.3 \%$ of CT+RT patients were expected to still be alive versus $80.79 \%$ of the Surg+RT group (Figure A). At the 5-year follow-up, 53.6\% of the patients treated with CT+RT were expected to still be alive versus $73.3 \%$ of those submitted to Surg+RT (Figure A).

A similar overall picture was observed for the disease-free survival group. The early period (24 months into treatment) revealed a drastic drop in the curve, indicating $51.7 \%(\mathrm{CT}+\mathrm{RT})$ and $70.6 \%$ (Surg+RT) of the patients without disease at this timepoint (Figure B). At the 5-year follow-up, 38.6\% of the CT+RT and $45.8 \%$ of the Surg+RT patients were expected to be free of disease (Figure B).

Similar survival rates were noticed for the resectable tumors, comparing lesions treated by Surg+RT versus $C T+R T$ ( $p>0.05$, Figure $C, D)$. Resectable tumors (grouping together those treated by Surg + RT and CT + RT) had overall survival rates similar to those of unresectable lesions ( $p>0.05$, Figure E), and a tendency toward better disease-free survival $(p=0.06$, Figure F).

Considering that the soft palate lesion rates found in each treatment group were different, and that these lesions usually present a distinct growth pattern and response to treatment, we performed a complementary survival analysis excluding these lesions. The same was done for $\mathrm{cN} 3$ stage tumors, considering that the presence of N3 metastasis, per se, deteriorates a patient's prognosis. None of these complementary analyses revealed differences in 
Advanced carcinoma of the oropharynx: survival analysis comparing two treatment modalities

Table 1. Clinical and demographic information on 47 patients with advanced squamous cell carcinoma of the oropharynx, according to two different treatment protocols.

\begin{tabular}{|c|c|c|c|c|c|c|c|}
\hline \multirow[b]{2}{*}{ Variables } & \multirow[b]{2}{*}{$\begin{array}{l}\text { All patients } \\
(\mathrm{n}=47)\end{array}$} & \multirow[b]{2}{*}{$\begin{array}{l}\text { Surgery }+ \\
\text { RT }(n=18)\end{array}$} & \multicolumn{3}{|c|}{$C T+R T(n=29)$} & \multicolumn{2}{|c|}{$p$-value ${ }^{a}$} \\
\hline & & & $\begin{array}{c}\text { Resectable, } \\
\text { but refused } \\
\text { surgery } \\
(n=11)\end{array}$ & $\begin{array}{c}\text { Unresectable } \\
\qquad(\mathrm{n}=18)\end{array}$ & $\begin{array}{c}\text { Total } \\
(n=29)\end{array}$ & $\begin{array}{c}\text { (all Surg + RT } \\
\text { patients versus } \\
\text { all CT+RT } \\
\text { patients) }\end{array}$ & $\begin{array}{l}\text { (all Surg +RT } \\
\text { patients versus } \\
\text { resectable } \\
\text { tumors treated } \\
\text { by } C T+R T \text { ) }\end{array}$ \\
\hline Age & & & & & & $0.964^{b}$ & $0.246^{b}$ \\
\hline Minimum & 36 & 36 & 43 & 41 & 41 & & \\
\hline Maximum & 79 & 75 & 67 & 79 & 79 & & \\
\hline Mean & 56.3 & 56.22 & 52.45 & 58.72 & 56.34 & & \\
\hline Sex & & & & & & 0.528 & 0.566 \\
\hline Female & $6(12.8)$ & $3(16.7)$ & $1(9.1)$ & $2(11.1)$ & $3(10.3)$ & & \\
\hline Male & $41(87.2)$ & 15 (83.3) & $10(90.9)$ & 16 (88.9) & $26(89.7)$ & & \\
\hline Smoking habit & & & & & & 0.306 & $\mathrm{~N} / \mathrm{A}$ \\
\hline Yes & $40(85.1)$ & $14(77.8)$ & 10 (90.9) & 16 (88.9) & 26 (89.7) & & \\
\hline No & $2(4.3)$ & 0 & 0 & $2(11.1)$ & $2(6.9)$ & & \\
\hline Missing & $5(10.6)$ & $4(22.2)$ & $1(9.1)$ & 0 & $1(3.4)$ & & \\
\hline Alcohol intake & & & & & & 0.193 & N/A \\
\hline Yes & $35(74.5)$ & $13(72.2)$ & $8(72.7)$ & 14 (77.8) & 22 (75.9) & & \\
\hline No & $3(6.4)$ & 0 & 0 & $3(16.7)$ & 3 (10.3) & & \\
\hline Missing & $9(19.1)$ & $5(27.8)$ & $3(27.3)$ & $1(5.6)$ & $4(13.8)$ & & \\
\hline cT stage & & & & & & 0.760 & 0.411 \\
\hline T3 & $17(36.2)$ & $7(38.9)$ & $6(54.5)$ & $4(22.2)$ & $10(34.5)$ & & \\
\hline $\mathrm{T} 4$ & $30(63.8)$ & $11(61.1)$ & $5(45.5)$ & 14 (77.8) & 19 (65.5) & & \\
\hline $\mathrm{cN}$ stage & & & & & & $0.025^{*}$ & 0.569 \\
\hline No & $14(29.8)$ & $4(22.2)$ & $5(45.5)$ & $5(27.8)$ & $10(34.5)$ & & \\
\hline $\mathrm{N} 1$ & $9(19.1)$ & $5(27.8)$ & 3 (27.3) & $1(5.6)$ & 4 (13.8) & & \\
\hline N2 & $11(23.4)$ & 7 (38.9) & $3(27.3)$ & $1(5.6)$ & $4(13.8)$ & & \\
\hline N3 & $12(25.5)$ & $1(5.6)$ & 0 & $11(61.1)$ & 11 (37.9) & & \\
\hline Missing & $1(2.1)$ & $1(5.6)$ & 0 & 0 & 0 & & \\
\hline TNM clinical staging & & & & & & 0.391 & 0.331 \\
\hline III & $10(21.3)$ & $5(27.8)$ & $5(45.5)$ & 0 & 5 (17.2) & & \\
\hline IV & $37(78.7)$ & $13(72.2)$ & $6(54.5)$ & $18(100)$ & $24(82.8)$ & & \\
\hline Subsite & & & & & & 0.182 & $0.027^{*}$ \\
\hline Tonsil & $13(27.6)$ & $3(16.7)$ & $4(36.4)$ & $6(33.3)$ & $10(34.5)$ & & \\
\hline Base of tongue & $17(36.2)$ & $9(50.0)$ & $1(9.1)$ & $7(38.9)$ & $8(27.6)$ & & \\
\hline Soft palate & $8(17.0)$ & $1(5.6)$ & $5(45.5)$ & $2(11.1)$ & $7(24.1)$ & & \\
\hline Posterior wall & $2(4.3)$ & $1(5.6)$ & 0 & $1(5.6)$ & $1(3.4)$ & & \\
\hline Lateral wall (tonsil pillars) & 7 (14.9) & $4(22.2)$ & $1(9.1)$ & $2(11.1)$ & $3(10.3)$ & & \\
\hline Recurrence & & & & & & 0.760 & 0.523 \\
\hline Yes & $17(36.2)$ & 7 (38.9) & $3(27.3)$ & 7 (38.9) & $10(34.5)$ & & \\
\hline No & $30(63.8)$ & $11(61.1)$ & $8(72.7)$ & $11(61.1)$ & 19 (65.5) & & \\
\hline
\end{tabular}

Continue 
Continuation

\begin{tabular}{|c|c|c|c|c|c|c|c|}
\hline Site of recurrence & & & & & & 0.119 & 0.055 \\
\hline Local & $5(29.4)$ & $3(42.9)$ & 0 & $2(11.1)$ & $2(20.0)$ & & \\
\hline Regional & $4(23.5)$ & $3(42.9)$ & 0 & $1(5.6)$ & $1(10.0)$ & & \\
\hline Loco-regional & $4(23.5)$ & 0 & $2(66.7)$ & $2(11.1)$ & $4(40.0)$ & & \\
\hline Distant & $4(23.5)$ & $1(14.3)$ & $1(33.3)$ & $2(11.1)$ & $3(30.0)$ & & \\
\hline Salvage $(n=17)$ & & & & & & 0.809 & N/A \\
\hline Yes & $2(11.8)$ & $1(14.1)$ & 0 & $1(14.3)$ & $1(10.0)$ & & \\
\hline No & $5(29.4)$ & $3(42.9)$ & 0 & $2(28.6)$ & $2(20.0)$ & & \\
\hline Missing & $10(58.8)$ & $3(42.9)$ & $3(100)$ & $4(57.1)$ & $7(70.0)$ & & \\
\hline Follow-up (months) & & & & & & $0.178^{b}$ & $0.759^{b}$ \\
\hline Minimum & 1 & 4 & 2 & 1 & 1 & & \\
\hline Maximum & 112 & 112 & 91 & 76 & 91 & & \\
\hline Mean & 34.91 & 42.28 & 38.55 & 25.33 & 30.34 & & \\
\hline Status at last follow-up & & & & & & 0.422 & 0.611 \\
\hline Alive without disease & $16(34.0)$ & $6(33.3)$ & $5(45.5)$ & $5(27.8)$ & $10(34.5)$ & & \\
\hline Local recurrence & $3(6.4)$ & $1(5.6)$ & 0 & $2(11.1)$ & $2(6.9)$ & & \\
\hline Regional recurrence & $2(4.3)$ & $2(11.1)$ & 0 & 0 & 0 & & \\
\hline Loco-regional recurrence & $4(8.5)$ & $2(11.1)$ & 0 & $2(11.1)$ & $2(6.9)$ & & \\
\hline Distant metastasis & $4(8.5)$ & $2(11.1)$ & $1(9.1)$ & $1(5.6)$ & $2(6.9)$ & & \\
\hline Death (disease-related) & 15 (31.9) & $3(16.7)$ & $4(36.4)$ & $8(44.4)$ & $12(41.4)$ & & \\
\hline Death (other causes) & $2(4.3)$ & $1(5.6)$ & $1(9.1)$ & 0 & $1(3.4)$ & & \\
\hline Missing & $1(2.1)$ & $1(5.6)$ & 0 & 0 & 0 & & \\
\hline pl6 & & & & & & 0.484 & 0.551 \\
\hline Positive & $3(6.4)$ & $1(5.6)$ & 0 & $2(11.1)$ & $2(6.9)$ & & \\
\hline Negative & $20(42.6)$ & $11(61.1)$ & $4(36.4)$ & $5(27.8)$ & $9(31.0)$ & & \\
\hline Not performed $^{c}$ & $24(51.1)$ & $6(33.3)$ & 7 (63.6) & $11(61.1)$ & $18(62.1)$ & & \\
\hline
\end{tabular}

RT: radiotherapy; CT: chemotherapy; Number in parenthesis represents percentages; N/A: statistics not performed because comparison group was null; a Pearson $x^{2}$; bStudent $T$ test; ${ }^{c}$ Specimen not available for immunohistochemical testing. ${ }^{*}$ statistically significant $(<0.05)$.

survival rates (overall and disease-free) between the two treatment modalities ( $p>0.05$, data not shown).

\section{Discussion}

The current study revealed similar overall and disease-specific survival rates of patients with advanced OP-SCC treated with Surg+RT, compared with CT+RT. An unfavorable clinical outcome was evidenced irrespective of treatment modality, with $34.0 \%$ patients alive without disease at the last follow-up. Importantly, similar survival rates were seen when cN3 disease and p16+ tumors were included (13.0\% prevalence in this study). The tendency toward a better disease-free survival rate observed for resectable tumors (grouping together those treated by Surg+RT and CT+RT) might be influenced by the higher volume of local and nodal disease present in the unresectable tumors, a scenario that represents a lower chance of disease control by chemoradiation. Accordingly, when analyzing only the resectable tumor group, there was no difference in the survival rates.

Taken together, the results are supportive of both modalities, Surg+RT and CT+RT, as being equally efficient in treating advanced OP-SCC. Therefore, 
Table 2. Surgical approach for patients treated with surgery and radiotherapy $(n=18)$

\begin{tabular}{|c|c|c|}
\hline Variables & Absolute number (\%) & $\mathrm{p}$-value (Pearson $\mathrm{x}^{2}$ ) \\
\hline Type of surgery & & 0.135 \\
\hline Base Glossectomy + total laryngectomy & $1(5.6)$ & \\
\hline Total Glossectomy + total laryngectomy & $3(16.7)$ & \\
\hline Pelveglossomandibulectomy & $6(33.3)$ & \\
\hline Transoral resection & $1(5.6)$ & \\
\hline Base glossectomy & $4(22.2)$ & \\
\hline Palatectomy & $1(5.6)$ & \\
\hline Pharyngectomy & $1(5.6)$ & \\
\hline Missing & $1(5.6)$ & \\
\hline Neck dissection & & $0.002^{*}$ \\
\hline None & $1(5.6)$ & \\
\hline Radical bilateral & $5(27.8)$ & \\
\hline Radical unilateral & $1(5.6)$ & \\
\hline Jugular bilateral & $1(5.6)$ & \\
\hline Radical + jugular & $10(55.6)$ & \\
\hline Surgical margin & & $0.003^{*}$ \\
\hline Negative (free) & $14(77.8)$ & \\
\hline Positive & $2(11.1)$ & \\
\hline Missing & $2(11.1)$ & \\
\hline
\end{tabular}

morbidity and functional sequelae should be taken into account when choosing the best treatment modality for a given patient, individually. Whereas Surg+RT carries the morbidity of partial resection of organs involved in speaking and swallowing, CT+RT is usually associated with malnutrition, dysphagia and risk of aspiration. These variables (morbidity and sequelae) were not taken into account in the current research.

In the last update ( $8^{\text {th }}$ Edition) of the AJCC guidelines, high-risk HPV-related oropharynx cancer was recognized as a unique disease, which usually affects young, non-smoking, non-drinking individuals, and presents an excellent response to treatment and good prognosis. ${ }^{9}$ Therefore, the immunohistochemical overexpression of p16 was adopted as a biomarker for HPV-related carcinogenesis. ${ }^{23}$ We found three p16-positive cases $(13.0 \%)$, corroborating the low prevalence (4.1\% to $14.3 \%)$ of HPV-related OP-SCC reported in Brazil. $19,24,25,26$ Importantly, only one of the three patients with p16+ tumors was a smoker and drinker. This patient had a worse clinical outcome (distant metastasis), whereas the other two (non-smokers and non-drinkers) remained alive without disease at the last follow-up. Accordingly, the results and interpretations of the survival analysis related herein mostly regard "conventional" OP-SCC, associated with tobacco and alcohol consumption. Finally, an interesting though specifically related observation was that the three p16-positive cases occurred in the tonsils and base of tongue, and the predilection of HPV-driven OP-SCC in the tonsils has already been addressed in the literature. ${ }^{20}$

HPV status has a strong influence on OP-SCC prognosis, and will probably drive treatment modality selection in the future. To date, modifying the treatment modality according to HPV status is still controversial, and should be undertaken only in clinical trials. ${ }^{27,28}$ For this reason, OP-SCC 
A

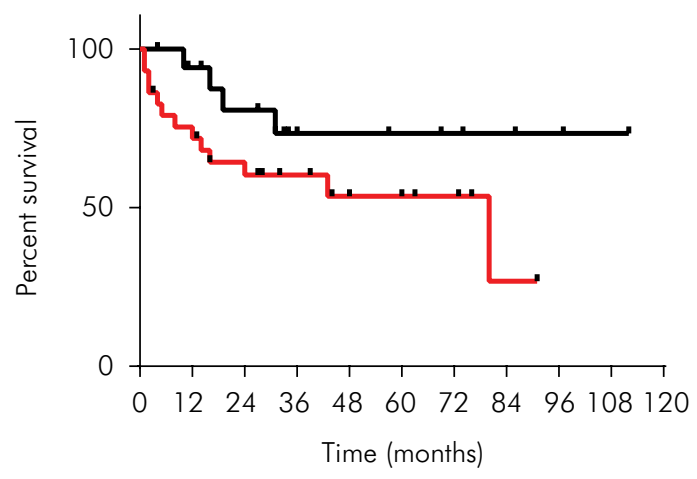

- Surg + RT - C CT + RT $\begin{aligned} & p=0.092 \\ & (\text { Log-rank) }\end{aligned}$

C Overall survival resectable tumors only

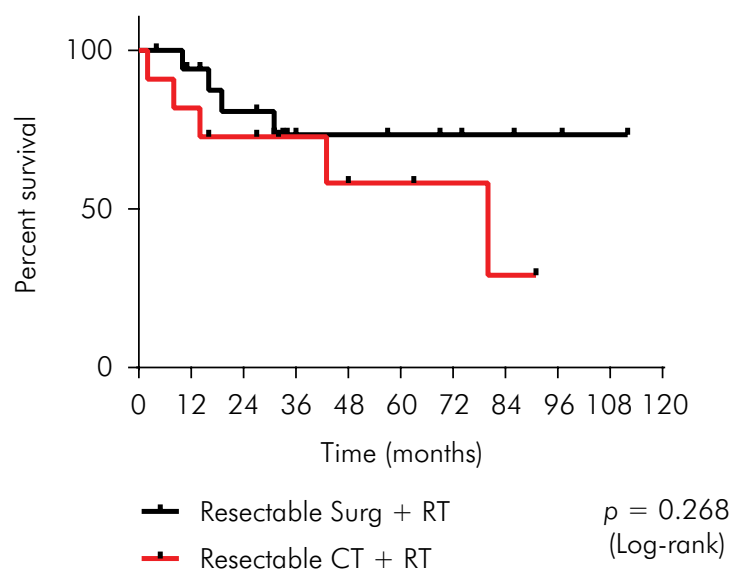

E Overall survival resectable $\mathrm{x}$ unresectable

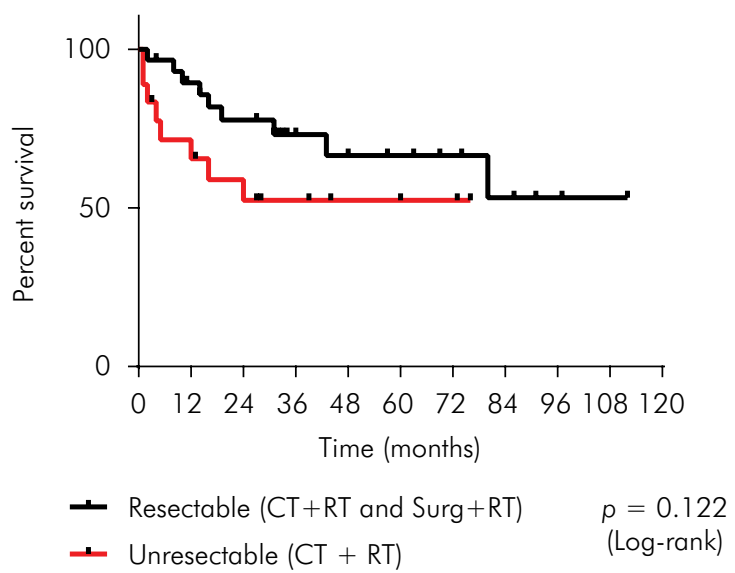

B

Disease-free survival

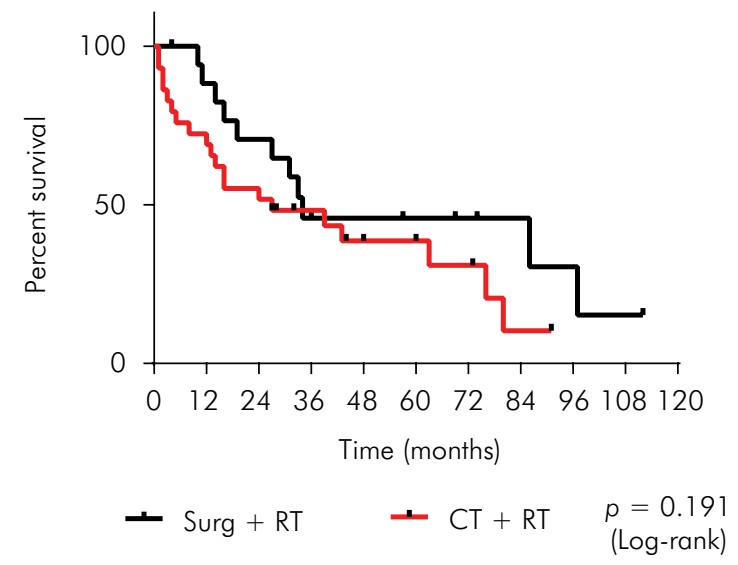

D Disease-free survival resectable tumors only

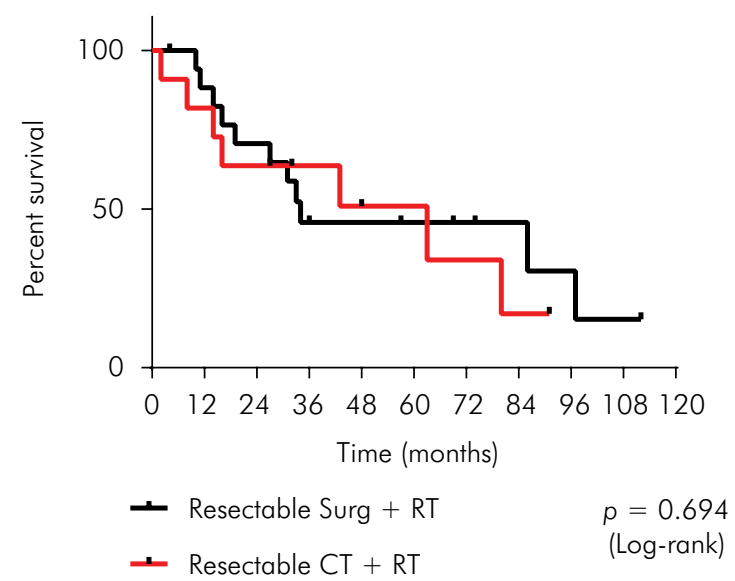

F Disease-free survival resectable $\mathrm{x}$ unresectable

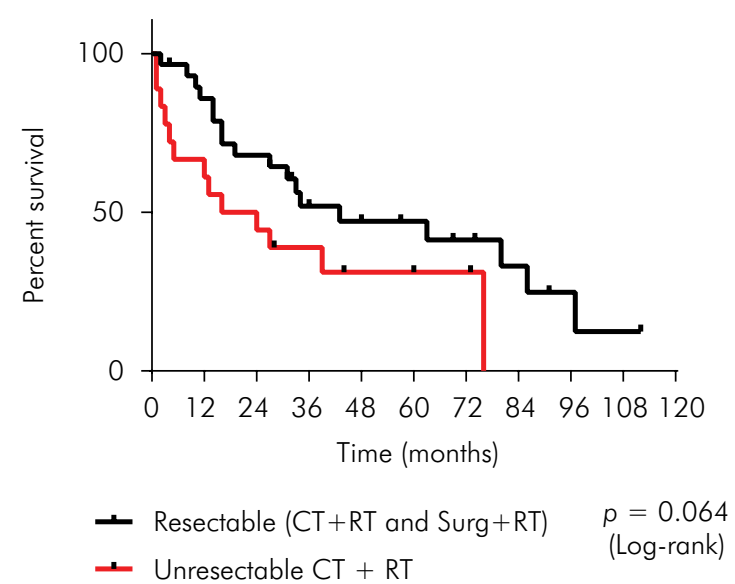

Figure. A, B: patients treated with surgery + radiotherapy (Surg +RT) had overall and disease-free survival rates similar to those treated by chemoradiotherapy $(C T+R T)(p>0.05)$. $C$, D: Similar overall and disease-free survival rates were noticed for resectable tumors, comparing lesions treated by Surg $+R T$ versus $C T+R T$ ( $p>0.05)$. E, F: Resectable tumors (treated by Surg $+R T$ and $C T+R T$, grouped together) presented similar overall survival rates with unresectable lesions $(p>0.05)$, and a tendency toward better disease-free survival rates $(p=0.06)$. 
is often treated with chemoradiation, although radiation and cetuximab may also be used in some cases. The effect of combining radiation with both chemotherapy and cetuximab is also being studied. Any lesion that remains after chemoradiation is removed with surgery. If the cancer has spread to neck lymph nodes, it may also have to be removed (by lymph node dissection) after chemoradiation. Another option is to surgically remove cancer and neck lymph nodes first. This is often followed by radiation or chemoradiation to reduce the recurrence rates. ${ }^{27,28}$ The treatment decision for individual patients will depend on the size, location and overall functional deficit of the tumor, as well as on patient preference and local expertise.

In our sample, relatively high percentages of patients were expected to be alive at the 5 -year survival follow-up (53.6\% and $73.3 \%$, respectively). On the other hand, a high recurrence rate was noticed at the 5-year survival follow-up (38.6\% and $45.8 \%$ ). Recurrences and deaths are considered important factors during the first two years of follow-up, especially for patients not treated with surgery, thus reinforcing the importance of strict surveillance after treatment. Lastly, most patients were smokers and drinkers, thus stressing that the association of oropharynx cancer with such deleterious social habits urges wide-ranging community health efforts to promote educational and preventive actions. ${ }^{20}$

\section{Conclusion}

In conclusion, the two treatment protocols, namely surgery + radiotherapy and chemotherapy + radiotherapy, were equally efficient in treating advanced oropharynx squamous cell carcinoma, considering that both promoted similar overall and disease-free survival rates. Therefore, the decision regarding each treatment modality should be taken on a case-by-case basis, assessing the patient's overall clinical picture for tolerating the protocol, the sequelae of each treatment, and the patient's expectations. The results and interpretations of the survival analysis related herein mostly regard the diagnosis of "conventional" OP-SCC, since p16+ tumors were very uncommon in the current sample.

\section{Acknowledgements}

This study had the support of PRPq/UFMGCNPq (PIBIC) \#05/2017; CNPq \#405585/2018-7. The funders had no influence in the study design, in the collection, analysis or interpretation of data, in the writing of the manuscript, or in the decision to submit the manuscript for publication.

\section{References}

1. Gillison ML, D'Souza G, Westra W, Sugar E, Xiao W, Begum S, et al. Distinct risk factor profiles for human papillomavirus type 16-positive and human papillomavirus type 16-negative head and neck cancers. J Natl Cancer Inst. 2008 Mar;100(6):407-20.

2. Clump DA, Bauman JE, Ferris RL. Cancer of the oropharynx. Surg Oncol Clin N Am. 2015 Jul;24(3):509-20. https://doi.org/10.1016/i.soc.2015.03.014

3. Bray F, Ferlay J, Soerjomataram I, Siegel RL, Torre LA, Jemal A. Global cancer statistics 2018: GLOBOCAN estimates of incidence and mortality worldwide for 36 cancers in 185 countries. CA Cancer J Clin. 2018 Nov;68(6):394-424. https://doi.org/10.3322/caac.21492

4. World HEALTH Organization. WHO Classification of head and neck tumours. Lyon: IARC; 2017.

5. Sturgis EM, Ang KK. The epidemic of HPV-associated oropharyngeal cancer is here: is it time to change our treatment paradigms? J Natl Compr Canc Netw. 2011 Jun;9(6):665-73. https://doi.org/10.6004/jnccn.2011.0055

6. Ramqvist T, Grün N, Dalianis T. Human papillomavirus and tonsillar and base of tongue cancer. Viruses. 2015 Mar;7(3):1332-43. https://doi.org/10.3390/v7031332

7. Ramqvist T, Mints M, Tertipis N, Näsman A, Romanitan M, Dalianis T. Studies on human papillomavirus (HPV) 16 E2, E5 and E7 mRNA in HPV-positive tonsillar and base of tongue cancer in relation to clinical outcome and immunological parameters. Oral Oncol. 2015 Dec;51(12):1126-31. https://doi.org/10.1016/j.oraloncology.2015.09.007

8. American Joint Committee on Cancer - AJCC. AJCC Cancer staging manual. 7th ed. New York: Springer; 2010.

9. American Joint Committee on Cancer-AJCC. AJCC Cancer Staging Manual. 8th ed. New York: Springer; 2017. 
10. Huang SH, Hansen A, Rathod S, O'Sullivan B. Primary surgery versus (chemo)radiotherapy in oropharyngeal cancer: the radiation oncologist's and medical oncologist's perspectives. Curr Opin Otolaryngol Head Neck Surg. 2015 Apr;23(2):139-47. https://doi.org/10.1097/MOO.0000000000000141

11. Huber MA, Tantiwongkosi B. Oral and oropharyngeal cancer. Med Clin North Am. 2014 Nov;98(6):1299-321. https://doi.org/10.1016/i.mcna.2014.08.005

12. Marur S, Forastiere AA. Head and Neck squamous cell carcinoma: update on epidemiology, diagnosis, and treatment. Mayo Clin Proc. 2016 Mar;91(3):386-96. https://doi.org/10.1016/j.mayocp.2015.12.017

13. Massano J, Regateiro FS, Januário G, Ferreira A. Oral squamous cell carcinoma: review of prognostic and predictive factors. Oral Surg Oral Med Oral Pathol Oral Radiol Endod. 2006 Jul;102(1):67-76. https://doi.org/10.1016/i.tripleo.2005.07.038

14. Rettig EM, D'Souza G. Epidemiology of head and neck cancer. Surg Oncol Clin N Am. 2015 Jul;24(3):379-96. https://doi.org/10.1016/i.soc.2015.03.001

15. Belcher R, Hayes K, Fedewa S, Chen AY. Current treatment of head and neck squamous cell cancer. J Surg Oncol. 2014 Oct;110(5):55174. https://doi.org/10.1002/jso.23724

16. Machiels JP, Lambrecht M, Hanin FX, Duprez T, Gregoire V, Schmitz S, et al. Advances in the management of squamous cell carcinoma of the head and neck. F1000Prime Rep. 2014 Jun;6:44. https://doi.org/10.12703/P6-44

17. Wilson L, Enepekides D, Higgins K. Management of oropharyngeal cancer: a cross-sectional review of institutional practice at a large Canadian referral centre. J Otolaryngol Head Neck Surg. 2014 Jun;43(1):19. https://doi.org/10.1186/1916-0216-43-19

18. Kreimer AR, Clifford GM, Boyle P, Franceschi S. Human papillomavirus types in head and neck squamous cell carcinomas worldwide: a systematic review. Cancer Epidemiol Biomarkers Prev. 2005 Feb;14(2):467-75. https://doi.org/10.1158/1055-9965.EPI-04-0551

19. Anantharaman D, Abedi-Ardekani B, Beachler DC, Gheit T, Olshan AF, Wisniewski K, et al. Geographic heterogeneity in the prevalence of human papillomavirus in head and neck cancer. Int J Cancer. 2017 May;140(9):1968-75. https://doi.org/10.1002/ijc.30608

20. Pytynia KB, Dahlstrom KR, Sturgis EM. Epidemiology of HPV-associated oropharyngeal cancer. Oral Oncol. 2014 May;50(5):380-6. https://doi.org/10.1016/j.oraloncology.2013.12.019

21. Pullos AN, Castilho RM, Squarize CH. HPV infection of the head and neck region and its stem cells. J Dent Res. 2015 Nov;94(11):1532-43. https://doi.org/10.1177/0022034515605456

22. Lewis JS Jr, Chernock RD. Human papillomavirus and Epstein Barr virus in head and neck carcinomas: suggestions for the new WHO classification. Head Neck Pathol. 2014 Mar;8(1):50-8. https://doi.org/10.1007/s12105-014-0528-6

23. Lydiatt WM, Patel SG, O'Sullivan B, Brandwein MS, Ridge JA, Migliacci JC, et al. Head and neck cancers-major changes in the American Joint Committee on cancer eighth edition cancer staging manual. CA Cancer J Clin. 2017 Mar;67(2):122-37. httpss://doi.org/10.3322/caac.21389

24. Betiol JC, Sichero L, Costa HO, de Matos LL, Andreoli MA, Ferreira S, et al. Prevalence of human papillomavirus types and variants and pl6(INK4a) expression in head and neck squamous cells carcinomas in São Paulo, Brazil. Infect Agent Cancer. 2016 May;11(1):20. https://doi.org/10.1186/s13027-016-0067-8

25. López RV, Levi JE, Eluf-Neto J, Koifman RJ, Koifman S, Curado MP, et al. Human papillomavirus (HPV) 16 and the prognosis of head and neck cancer in a geographical region with a low prevalence of HPV infection. Cancer Causes Control. 2014 Apr;25(4):461-71. https://doi.org/10.1007/s10552-014-0348-8

26. Hauck F, Oliveira-Silva M, Dreyer JH, Perrusi VJ, Arcuri RA, Hassan R, et al. Prevalence of HPV infection in head and neck carcinomas shows geographical variability: a comparative study from Brazil and Germany. Virchows Arch. 2015 Jun;466(6):685-93. https://doi.org/10.1007/s00428-015-1761-4

27. O'Sullivan B, Huang SH, Siu LL, Waldron J, Zhao H, Perez-Ordonez B, et al. Deintensification candidate subgroups in human papillomavirus-related oropharyngeal cancer according to minimal risk of distant metastasis. J Clin Oncol. 2013 Feb;31(5):543-50. https://doi.org/10.1200/JCO.2012.44.0164

28. Moore EJ, Hinni ML. Critical review: transoral laser microsurgery and robotic-assisted surgery for oropharynx cancer including human papillomavirus-related cancer. Int J Radiat Oncol Biol Phys. 2013 Apr;85(5):1163-7. https://doi.org/10.1016/i.ijrobp.2012.08.033 